\title{
PREDICTING DECISION-MAKER MOMENTUM TO CHANGE OFFERINGS IN RESPONSE TO UNCERTAINTY: The CASE OF THE U.S. CuSTOMS MOD ACT
}

\author{
Carolyn M. Jones Carr \\ Strategic Response Technologies, Inc. \\ Indianapolis, IN \\ Charles B. Shrader \\ Michael R. Crumm \\ Iowa State University \\ Ames, IA \\ E. James Flynn \\ Wake Forest University \\ Winston-Salem, NC
}

\begin{abstract}
The major concern of this paper is predicting decision-maker momentum to change product and service offerings in response to significant uncertainties as an antecedent to organizational change. From a survey of organizations in the National Customs Brokers and Forwarders Association of America (NCBFAA), data were obtained on decision-makers" perceived uncertainties, and intent or momentum to change offerings in response to uncertainty created by the U.S. Customs Modernization and Informed Compliance Act of 1993 (Mod Act). Survey measures include uncertainties, organization revenue and age, decisionmaker age and experience, technological expertise, formal planning and formalization of procedures. The regression results indicate that organization revenue, decision-maker age and Mod Act uncertainty were associated with the NCBFAA customs brokers' momentum to change offerings in response to Mod Act uncertainty. Because the survey can be adapted for industry-specific uncertainties, we propose the survey, model and its results can be used by decisionmakers of organizations within dynamic industries as they seek to realign to a new industry environment.
\end{abstract}

\section{Introduction}

The organizational transformation process is usually regarded as a deliberate effort of an organization to move from a current to a desired organizational state to better "fit" with a dynamic industry environment (Mukherji, Desai, \& Francis, 1999). Researchers (Bamford, Rogers, \& Miller, 1999; Lieberson \& O'Connor, 1972) maintain that beliefs and expectations of the dominant coalition (i.e., 
CEO, president, top management, and board members) are formalized based on their perception of what environmental phenomena are relevant for the health of the organization. In their study of antecedents for organizational change, Bamford et al. (1999) found that change in the dominant coalition is a significant antecedent to organizational change. This body of work shows the importance of decision-maker perceptions. Additionally, Hamel and Prahalad's (1989) research on strategic intent, Child's (1972) research linking strategic choice and strategic response, and Hitt and Tyler's (1991) argument that decision-makers use a set of objective criteria from the organization's external and internal environment to decide on an intended strategy, provide evidence that strategic intent can be seen as a first step to organizational change. Based on this body of work, we propose that predicting decision-maker momentum to change offerings in response to environmental uncertainty may be seen as an antecedent for organizational change.

Dutton and Duncan's "Strategic Issue Diagnosis" conceptual model (1987) provides the theoretical framework for the empirical model. Dutton and Duncan's conceptual model focuses on how decision-makers' perceptions of uncertainties and response feasibility may generate a strong or weak momentum for organizational change. In their work, they argue that decision-makers may recognize an uncertainty as significant for their organization's health. However, if response feasibility (i.e., resource availability and decision-maker risk propensity) is low, the overall momentum for organizational change may be low. Furthering Dutton and Duncan's (1987) conceptual work, we develop and test an integrative model (Rajagopalan \& Spreitzer, 1996) to predict decision-maker momentum to change offerings in response to environmental and firm structure uncertainties. We also identify the specific environmental uncertainties and organization characteristics from those included in the model that are significantly related to decisionmaker momentum to change offerings in response to environmental uncertainty. Moreover, Burgelman and Doz (1997) discuss the importance of models/tools decision-makers can use in performing complex strategic integration (CSI). According to Burgelman and Doz, more decision-makers are utilizing complex strategic integration tools in the development of corporate strategies to exploit new growth opportunities and better utilize knowledge resources across business units. Consistent with Burgelman and Doz's comments on the importance of CSI models and Kent D. Miller's 1993 study, this research develops and tests a perceived uncertainty measurement instrument grounded in strategic management theory.

Consistent with Burgelman and Doz, the proposed model can be useful to decision-makers of organizations during the transformation process as they seek to realign to a dynamic environment. For example, if decision-makers view an uncertainty as relevant for organizational change, but response feasibility is low, decision-makers can consider strategies for expanding resources (e.g., strategic alliances). In another example, if decision-maker risk tolerance is negatively related to decision-maker momentum to change offerings, then decision-makers 
may change the membership of the dominant coalition to include more risk tolerant members. In another example, if technological expertise is positively related to decision-maker momentum to change offerings, then decision-makers can consider strategies to increase technological expertise. Moreover, if formal planning is positively related to decision-maker momentum to change offerings, then decision-makers may decide formal planning benefits the organization. In a final example, if no uncertainties were perceived as significant, decisionmakers may decide no organizational change is required. As noted by Gersick (1994) decision-makers must make a complex but fundamental choice to change course or stay on the same path.

In this study, we define organizational change as change in offerings. The population of interest is the NCBFAA because it is the largest customs brokers' association and all member organizations have equal access to information. We obtain perceptions of key decision-makers of member organizations during the period of uncertainty between passage of the Mod Act in 1993 and prior to the final implementation of the Mod Act rules expected in 1998. We develop and test a regression model with macro, industry and internal categories of environment variables (Mukherji et al., 1999) to predict decision-maker momentum to change offerings in response to environmental uncertainty. Finally, we present conclusions and discuss implications for practitioners.

\section{The Mod Act}

The context for this study is the NCBFAA and its members' momentum to change offerings in response to the uncertainties created by the passage of the Mod Act. The Mod Act was enacted with the North American Free Trade Agreement (The NAFTA) on December 8, 1993. However, the final rules of implementation and subsequent enactment of the Mod Act were not expected to be complete until 1998. The primary goal of the Mod Act legislation was to efficiently speed the processing of exports from and imports into the United States. Implementation of the Mod Act was expected to directly impact the types of services demanded of U.S. customs brokers, the risk exposure for U.S. customs brokers, and the technology capabilities required of U.S. customs brokers.

The customs broker function plays a significant role in the international supply pipeline. Most formal import entries are handled by customs brokers who are licensed by U.S. Customs to represent clients- individuals and firms- in U.S. Customs matters. The activities performed by customs brokers include assessing the admissibility, valuation and classification of merchandise, while maintaining the integrity of import/export laws and security of the U.S. At the time the Mod Act was passed, there were approximately nine thousand U.S. customs brokers working as agents or as members of customs broker organizations.

Prior to the passage of the Mod Act, it was estimated that automation of U.S. Customs' clearances resulting from the Mod Act could decrease revenues from traditional services provided by U.S. customs brokers by as much as $80 \%$. It was 
suggested by Jones Carr and Crum (1995) that the Mod Act regulations could lead to organization failures and significant industry consolidation through mergers, acquisitions and strategic alliances. The Mod Act was expected to significantly affect U.S. customs broker efficiency in three key ways (Jones, Carr, \& Crum, 1995): 1) by reducing bottlenecks at ports, 2) by outsourcing certain responsibilities to others in the supply pipeline thereby reducing administrative costs, and 3) through increased automation and reduction of paperwork. The Mod Act streamlines the U.S. Customs process by reducing both the number of entries requiring formal validation and the number of entries requiring the service of customs brokers. For more specifics on the intended service changes of the NCBFAA customs brokers at the time of the survey, see Table 1.

Table 1

Broker services expected to be offered by more than $50 \%$ more firms between 1993 and 1998

\begin{tabular}{lccc}
\hline Service & $\begin{array}{c}\text { \% Increase in } \\
\text { No. of Firms }\end{array}$ & $\begin{array}{c}\text { No. of Firms } \\
\text { Offering in 1993 }\end{array}$ & $\begin{array}{c}\text { No. of Firms } \\
\text { Planning to } \\
\text { Offer in 1998 }\end{array}$ \\
\hline Trade compliance & $40 \%$ & 47 & 66 \\
Contract logistics & $67 \%$ & 21 & 35 \\
Shipper alliances & $56 \%$ & 27 & 42 \\
Cargo control & $64 \%$ & 28 & 46 \\
Shipment tracking & $57 \%$ & 37 & 58 \\
Purchase order tracking & $208 \%$ & 12 & 37 \\
Freight inventory control & $150 \%$ & 14 & 35 \\
On-line invoicing & $28 \%$ & 13 & 50 \\
Ocean logistics & $106 \%$ & 18 & 37 \\
Global communication & $6 \%$ & 26 & 44 \\
\hline
\end{tabular}

\section{Measuring Decision-maker Perceptions of Uncertainties}

Boyd, Dess and Rasheed (1993) make several recommendations for using perceptual measures. First, it is important to note in a study that environmental uncertainties vary across industries and within an industry over time. Second, findings from a single study are situation specific and limited by the variables used in measurement of key constructs. Third, measurement instruments should be validated over time.

With respect to Boyd, Dess and Rasheed's first and second recommendations, we propose that the model in this study can be used by decision-makers of organizations within industry associations to get a snapshot of specific uncertainties during a period of uncertainty as they seek to realign to a changing 
industry environment (e.g., regulatory change). With respect to Boyd, Dess and Rasheed's third recommendation, we present prior research that supports our methodology.

In Miller's (1993) research on industry and country effects on decisionmakers' perceptions of environmental uncertainties, he describes a shortcoming in existing uncertainty literature as the tendency to isolate specific decisionmaker uncertainties to the exclusion of other uncertainties. Researchers (Miller, 1993; Lewis \& Harvey, 2001; Mukherji, Desai, \& Francis, 1999) support three broad levels of decision-maker uncertainty variables in perceived uncertainty measurement instruments: 1) macro, 2) industry, and 3) organization-specific.

Miller (1993) also describes the problem of aggregating decision-maker perceptions of uncertainties from a diverse range of environmental components into a single uncertainty measure (Lawrence \& Lorsch, 1967; Duncan, 1972). Miller argues the pooling of perceived uncertainty scores from diverse components into a single scale presumes uncertainty is a one dimension construct. More recent research (Miller, 1993; Lewis \& Harvey 2001; Hrebiniak \& Snow, 1980; Mulford, Shrader, \& Hansen, 1988; Miles \& Snow, 1978) purports the view that decision-makers perceive differences in the levels of uncertainty associated with distinct environmental components. Their measurement instruments reflect this view by using factor analysis loadings to aggregate uncertainties or by using individual constructs. Consistent with this body of work, we use factor analysis loadings to aggregate external environment variables. All other variables in the regression model are distinct constructs.

The specific macro, industry and organization-specific variables we included in the model are supported by Miller's (1993) typology of uncertainties. According to Miller, his uncertainty typology scale is most similar to Miles and Snow's (1978) uncertainty typology. Recent research by Lewis and Harvey (2001) extends Miller's scale to the natural environment. The uncertainty categories in Miller's scale broadly include: 1) government and policies, 2) economy, 3) resources and services used by your company, 4) product market and demand, 5) competition, and 6) technology in your company. The regression model in this research incorporates variables that are consistent with Miller's uncertainty typology.

Finally, consistent with Boyd, Dess, and Rasheed's recommendations, recent research by Carpenter and Frederickson (2001) and Hult, Hurley, Giunipero, and Nichols (2000) suggests that organizational responses to uncertainty are best examined within specific demographics and within given functions. To this end this research examines U.S. customs brokers in the NCBFAA working within the U.S. Customs function in context of Mod Act change during a period of uncertainty between the passage of the Mod Act in 1993 and its anticipated implementation in 1998. Therefore, we hypothesize:

Hypothesis la: As perceived Mod Act (MOD) uncertainty increases, the NCBFAA customs brokers'momentum to change offerings will increase. 
Hypothesis $1 \mathrm{~b}$ : As perceived other uncertainty (ENV) increases, the NCBFAA customs brokers' momentum to change offerings will increase.

\section{Organization Characteristics and Decision-maker Momentum to Change Offerings}

In this section we discuss the organizational characteristics we include in the model. The variables include organization size and age, formal planning, formalization of procedures and technological expertise.

\section{Organization size}

Variyam and Kraybill (1997) and Scherer (1970) suggest that smaller organizations generally face more financial uncertainty than larger organizations because of differences in market power. Capital and labor constraints also limit small organizations' ability to adopt risky, innovative strategies in response to environmental uncertainty (e.g., Wiersema \& Bantel, 1992; Kimberly \& Evanisko, 1981). Birnbaum (1984) also proposed that large organizations may have greater available resources because they have more capital and human assets. Thus, a larger organization may have a greater capacity to respond to uncertainties. In particular, larger organizations may have a greater capacity to respond to technological recordkeeping and auditing requirements associated with regulatory changes where the cost burden may be prohibitive for small organizations.

Consistent with Dutton and Duncan's (1987) conceptual link between available revenue and response feasibility, we define organization size narrowly as revenue that can be utilized to increase both capital and knowledge resources. Finally, based on Boyd, Dess and Rasheed's (1993) article, the organization size measure is both archival and perceptual because we ask decision-makers with revenue knowledge to indicate a range that includes their organization's current annual revenue.

\section{Organization age}

Mulford et al. (1988) found that older organizations do less planning than younger organizations. Variyam and Kraybill (1997) reported consistent findings and concluded that the relative lack of planning by older organizations in their study may partly explain their lower growth rates. Variyam and Kraybill also found that organization age helped to account for industry-specific knowledge resources accumulated within the organization. With respect to organization growth, Jovanovic (1982) suggested that organization age represents the learning process as the organization adjusts output and size to efficiently respond to changes in demand. Consequently, older organizations have been associated with greater industry-specific knowledge resources, and arguably, with greater decision-maker momentum to change offerings in response to environmental uncertainties. 


\section{Formal planning and formalization of procedures}

Porter (1985) indicates that formal planning and scenario building may improve an organization's ability to develop and implement a well-defined strategic response. In particular, small organizations may benefit from formal planning (e.g., Mulford, Shrader, \& Hansen, 1988; Shrader, Mulford, \& Blackburn, 1989). While formal planning and formalization of procedures may benefit many organizations, it is important to note that many small organizations do not have formal plans or formalize procedures (e.g., Mulford, Shrader, \& Hansen, 1988; Shrader, Mulford, \& Blackburn, 1989). Also, several researchers (Tushman \& Romanelli, 1985; Mintzberg, 1979; Child, 1972; Scherer, 1970) have concluded that as organization size increases, formal planning and formalization of procedures may increase complexity (Quinn \& Cameron, 1983), decrease strategic thinking (Mintzberg, 1979), and decrease innovation (Child, 1972; Scherer, 1970). Moreover, researchcrs (Papadakis, Lioukas, \& Chambers (1998); Thompson (1967); Kukalis, 1989 ) found that rule formalization of procedures and propensity to adapt are negatively related in cases of high "decision" uncertainty because decision-makers tend to act in an "inspirational" manner rather than follow formal plans and procedures. Because of the Mod Act's recordkeeping requirements, we hypothesize that both formal planning and formalization of procedures are more likely to be positively related to decision-maker momentum to change offerings in response to regulatory change.

\section{Technology}

Variyam and Kraybill (1997) reported in their study that formal planning and the use of new or advanced technology are critical to small organization survival. Also, Link and Bozeman (1991) found that larger organizations have a higher propensity to acquire technical knowledge and adopt new technology. Thus, increasing technological expertise may be seen as a strategic intent that can be used to respond to perceived external environmental threats and opportunities. Moreover, large organizations may be more likely than small organizations to succeed in increasing their technological expertise.

Based on the above discussion of organization size, organization age, formal planning, formalization of procedures and technology, we propose these hypotheses:

Hypothesis 2: As organization size (SIZE) increases, the NCBFAA customs brokers 'momentum to change offerings will increase.

Hypothesis 3: As organization age (AGEF) increases, the NCBFAA customs brokers 'momentum to change offerings will increase. 
Hypothesis 4: As formal planning (PLAN) increases, the NCBFAA customs brokers'momentum to change offerings will increase.

Hypothesis 5: As formalization of procedures (FORM) increases, the NCBFAA customs brokers' momentum to change offerings will increase.

Hypothesis 6: As experience with technology increases (TECH), the NCBFAA customs brokers' momentum to change offerings will increase.

\section{Decision-maker Characteristics and Their Momentum to Change Offerings}

A growing body of research provides support for the criticality of decisionmaker demographics in creating a fit between the environment and the organization (Wiersema \& Bantel, 1992, Wiersema \& Bantel, 1993; Hambrick \& Mason, 1984; Kimberley \& Evanisko, 1981; Mulford, Shrader, \& Hansen, 1988, Norburn \& Birley, 1988). Alternatively, Lieberson and O'Connor (1972) conclude that leadership influences corporate performance less than environmental or organizational factors. While arguably less critical than environmental uncertainty or organizational factors, decision-maker demographics are important in organizational realignment. As summarized by Tushman and Romanelli (1985): "Where environments are changing and/or performance outcomes are low or declining, leadership's primary task is to intervene on ongoing patterns of commitment and exchange to redirect the character of an organization's relationship with its environment." Hambrick and Mason (1984) place primary emphasis on observable decision-maker characteristics as indicators of the alignment skills that decision-makers bring to their management positions. With this approach, they focus on broad tendencies for change. Lastly, Hitt and Tyler's (1991) findings support the negative effects of age and the positive effects of decision-maker experience with respect to organizational realignment to environmental uncertainties.

\section{Decision-maker age}

Hambrick and Mason (1984) found that younger decision-makers pursue riskier strategies than do older decision-makers. Therefore, one may infer that decision-maker momentum to change offerings to environmental uncertainty is negatively related to decision-maker age. Moreover, Child (1972) found that youthfulness is related to risk propensity. Additionally, Hart and Mellons (1970) found the ability to consider commercial solutions from a wider set of options is related to risk propensity. Finally, Schuman and Scott (1989) support the proposition that the generational character of the events experienced by decisionmakers in their youth exerts an important influence on the weightings accorded to various decision criteria. Thus, younger decision-makers might not only have 
a higher momentum for organizational change in response to environmental uncertainties, but might also weight criteria in the decision-making process differently from older decision-makers.

Hypothesis 7: As decision-maker age (AGEM) increases, the NCBFAA customs brokers 'momentum to change offerings will decrease.

\section{Decision-maker experience}

In a 1997 study, Boeker examined how chief decision-maker characteristics interact with organizational performance to influence strategic change. His results support the contention that decision-maker experience and diversity positively impact strategic change. Moreover, Hambrick and Mason (1984) argued that decision-makers' cognitive models are based in part on their career experiences. Hitt and Tyler (1991) and Carpenter and Frederickson (2001) contend that experience in multiple functions may enrich decision-makers' strategic decision-making abilities. Hitt and Tyler also found that the total career experience, possessed by a decision-maker, moderates the relationship between the decision criteria and decision-maker momentum for organizational change. Based on this body of work, we hypothesize that more experienced decisionmakers would be more likely to be involved in the decision-making process.

Hypothesis 8: As decision-maker experience (EXPM) increases, the NCBFAA customs brokers' momentum to change offerings will increase.

\section{Model Specification}

The regression model incorporates individual variables for Mod Act uncertainty and other uncertainty, organization size and age, decision-maker age and experience, technological expertise, formal planning and formalization of procedures. The dependent variable is decision-maker momentum to change offerings. The independent variables have been researched extensively regarding their connection to strategic change. The choice of variables included in this model has been discussed and the hypotheses have been presented.

The following regression model was developed to reflect the aforementioned factors hypothesized to affect decision-makers' momentum to change offerings: DECISION-MAKER MOMENTUM TO CHANGE OFFERINGS $=$ MOD + $\mathrm{ENV}+\mathrm{SIZE}+\mathrm{AGEF}+\mathrm{PLAN}+\mathrm{FORM}+\mathrm{TECH}-\mathrm{AGEM}+\mathrm{EXPM}$ where, DECISION-MAKER MOMENTUM TO CHANGE OFFERINGS = the number of intended offering changes decision-makers perceive will occur between 1993 (Mod Act passed) and 1998 (when the final Mod Act rulings were expected to be complete) $\mathrm{MOD}=\mathrm{Mod}$ Act uncertainty; ENV = other environmental uncertainty; SIZE = organization size; $\mathrm{AGEF}=$ age of organization; PLAN = formal 
planning; FORM = formalization of procedures; $\mathrm{TECH}=$ technical experience of organization; $\mathrm{AGEM}=$ age of top decision-maker; $\mathrm{EXPM}=$ experience of top decision-maker. (Please refer to Table 2 for a summary of the sources of these measures.)

Table 2

Scales from previous research and new scales to be tested by questionnaire

\begin{tabular}{lll}
\hline Independent Variables & Source & Definition \\
\hline MOD & $\begin{array}{l}\text { Modified from Mulford, } \\
\text { Shrader \& Hansen (1988) } \\
\text { Specific uncertainties/measure } \\
\text { developed by Jones Carr (1997) }\end{array}$ & Mod Act uncertainty \\
& $\begin{array}{l}\text { Modified from Mulford, } \\
\text { Shrader, \& Hansen (1988) }\end{array}$ & Other uncertainties \\
ENV & $\begin{array}{l}\text { Specific uncertainty factors/measure } \\
\text { developed by Jones Carr (1997) }\end{array}$ & \\
& Birnbaum (1984) & Firm size \\
Variyam and Kraybill (1997) & Age of firm \\
AGEF & Mulford, Shrader \& Hansen (1988) & Formal planning \\
PLAN & Mulford, Shrader \& Hansen (1988) & Formal procedures \\
FORM & Variyam and Kraybill (1997) & Technological expertise \\
TECH & Hitt and Tyler (1991) & Decision-maker age \\
AGEM & Hitt and Tyler (1991) & $\begin{array}{l}\text { Decision-maker } \\
\text { Experience }\end{array}$ \\
EXPM & Jones Carr (1997) & $\begin{array}{l}\text { Number of service } \\
\text { changes }\end{array}$ \\
\hline Momentum to Respond & & \\
& &
\end{tabular}

\section{Dependent Variable}

The measure for decision-maker momentum to change offerings is defined as the absolute value of the intended changes in offerings between 1993 when the Mod Act passed into law and 1998 when the final Mod Act rulings were expected to be implemented. We chose this period of time, because it represented a period of uncertainty where decision-makers could adapt to the changes embodied in the Mod Act. The decision-maker momentum to change offerings measure was developed for this research by compiling a list of service offerings in the marketing and promotion literature acquired from randomly selected large customs brokerage organizations. NCBFAA survey respondents were asked to check those services they offered in 1993, 1995, and 1998 (planned). The absolute value of intended changes was then calculated for each respondent and used as 
the value for the dependent variable for each of the respondents. We use absolute value to calculate the dependent variable because we are interested in the level of momentum to change offerings, irrespective of whether decision-makers intend to add or subtract offerings.

\section{Independent Variables}

Mod Act uncertainty (MOD) and other environmental uncertainty (ENV). These measures were modified from Mulford, Shrader and Hansen (1988) and based on a thorough review of the strategic management literature, logistics trade literature and Mod Act legislative hearing reports. Uncertainty resulted from four major changes contained in the Mod Act: 1) remote entry, 2) U.S. Customs reorganization, 3 ) increased minimum values for formal entry, and 4) shifting responsibility and record-keeping requirements. Extensive research identified these time-specific causes of industry uncertainty: 1) the organization's customers, 2) the organization's competitors, 3) global trade developments (i.e., EU, NAFTA, GATT/WTO), and 4) technological requirements. The respondents were asked to indicate how certain they were of the expected consequences of MOD and ENV for their organization on a Likert scale from one to seven where one was not sure and seven was sure.

Decision-maker age. This measure was modified from Mulford, Shrader and Hansen (1988). The titles of the individuals who completed the questionnaire were reviewed to ensure that each was in a key decision-maker position. All respondents were CEOs, Owners, Partners, Presidents, Vice Presidents, or key decision-makers with responsibility for responding to changes in the environment. Specifically, there were 38 Presidents, 24 Vice Presidents, 14 import managers, 6 owners, $5 \mathrm{CEOs}$ and 2 treasurers. Respondents were asked to indicate their age category: under $25,26-35,36-45,46-55$, and over 55 . These categories were translated into values from 1 to 5 .

Decision-maker experience. Decision-maker experience is measured as the number of years the decision-maker was in the customs broker industry or a related field. This measure represents a surrogate for decision-maker experience.

Formal Planning. Formal Planning is an eight-item measure that was modified from a previously validated measure by Mulford et al. (1988). The respondents were asked to circle the appropriate response. A reliability measure was developed for formal planning based on the Mulford et al. (1988) study. Cronbach Alpha was calculated to determine the maximum likelihood estimate of the reliability coefficient if the parallel model is assumed to be true. The measure for formal planning includes assigning a value of zero for those organizations that did not formally plan and a one for those organizations that did formally plan. For those organizations that did formally plan, all circled items for the following questions were summed. This value was then used in the regression model for formal planning.

The measure includes these questions: 1) Does your long-range plan include quantified objectives for any of the following: earnings, capital growth, sales/ earnings ratio, return on investment, or share of the market? 2) Does your long 
range plan include the following pro forma (future) financial statements: balance sheet, income statement or cashflow analysis? 3) Does your long range plan include plans and budgets for the following: hiring/training management personnel, capital investments, advertising, or industry research? 4) Does your long range plan specifically attempt to identify any of the following: political developments, social currents, personnel attitudes, technological breakthroughs, owner incomes, or global economic trends?

Formalization of procedures. Formalization of procedures is a two-item measure that was developed for this research. For this measure, we assign a value of zero or one. The sum of the values for these two questions is the value used in the regression model. The questions for this measure include the yes/no questions: 1) Are there written guidelines or a manual specifying agency procedures or organizational procedures for staff directly or indirectly involved in providing services? 2) Is each employee supplied his or her own manual?

Organization Size. Noting the importance of organization size with respect to available resources in Dutton and Duncan's (1987) conceptual work, we utilized the Small Business Administration's (SBA) definition of a small business for this research. A small business is defined by the SBA as one with $\$ 3.5$ million annual revenue or less. We provided respondents with several revenue range categories and asked them to check the range for their organization's current annual revenue. The respondents' answers were collapsed into two categories based on the SBA definition: 1) organizations with more than 3.5 million current annual income, and 2) organizations with less than or equal to 3.5 million in current annual income. Values of zero for small organizations and one for large organizations were assigned for use in the regression model.

Organization Age. This measure was developed by Mulford et al. (1988). As in their study, we used age of organization in years in the regression model.

Technological Expertise. This measure was modified from a measure developed by Mulford et al. (1988). We asked the respondents to provide us with the number of employees in average full-time equivalents for the following employee categories: customs brokers, information system employees, regulatory advisors and logistics service employees. These categories were summed to provide a value for the regression model.

\section{Methodology}

The sampling strategy and statistical methods used to analyze the uncertainty variables and other explanatory factors are discussed below. The results of this analysis reveal a fairly robust model that may have practical use for decisionmakers of organizations faced with a turbulent industry environment.

\section{Sampling}

Surveys were mailed to all 501 U.S-based members listed in the 19941995 directory of the National Customs Brokers and Forwarders Association 
of America (NCFAA). Because we are focusing on the NCBFAA Customs Brokers and their perceived momentum to change offerings in response to environmental uncertainty, we will not make inferences with respect to a larger population of customs brokers. Usable responses were received from 89 customs brokers for an effective response rate of $17.8 \%$. Because of our small population we believe this response rate is acceptable. However, only 64 complete responses were usable for regression analysis because of missing responses. Two factors contributed to the low response rate: 1) the survey was lengthy to incorporate measures for two areas of research interest: logistics measures to explore channel integration, and measures to predict decision-maker momentum to change offerings, and 2) more effort needed to be undertaken to ensure respondents were aware that one blank response for any of the measures included in the regression analysis would eliminate all of the respondent's responses from the regression analysis. This is similar to a problem faced by Miller (1993).

The NCBFAA was chosen as the target sample because it is the largest association of customs brokers in the United States and because the association provides equal access to information to all of its members. This eliminated the need for a control variable (O'Reilly, 1982).

\section{Determining Uncertainty Constructs}

The eight uncertainty factors in MOD and ENV were factor analyzed, as a group, to determine if these two measures indeed represent two different constructs. As reported in Table 3, principal components factor analysis reveals that this is the case. The Cronbach alpha values ( 0.86 for MOD and 0.76 for ENV) provide further support that these two variables are measuring separate causes of uncertainty. Factor analysis further identified remote entry as the single most important factor for MOD and customer uncertainty as most important for ENV. Each of these factors was also the only one in its construct with an Eigenvalue greater than one. An alternative to using the multi-factor constructs for uncertainty would be to utilize Porter's suggestion that only the most important factor explains or determines strategic response. Thus, MOD was reduced to uncertainty resulting from remote entry (i.e., MOD) and ENV was reduced to customer uncertainty (i.e., ENV). This finding is further supported by responses to a series of questions pertaining to perceptions of how organization strategy and industry structure might change in response to the Mod Act. Remote entry clearly was viewed as the most influential factor by respondents.

\section{Diagnosing Multicollinearity}

Because of several significant correlations examined in partial correlation coefficient analysis, we tested directly for multicollinearity (see Tables 4 and 5) using the Ridge Method, Principal Components Analysis and the Durbin-Watson test. With respect to the residual scatterplot, there was no visible pattern of correlation among variables, and all standard deviations were between zero and three. 
Table 3

Results of factor analysis of uncertainty variables

\begin{tabular}{|c|c|c|c|c|c|c|}
\hline Factors & Item & Loading & Eigenvalue & $\begin{array}{c}\% \\
\text { Variable } \\
\end{array}$ & $\begin{array}{l}\text { Mean } \\
\text { (STD) }\end{array}$ & $\begin{array}{c}\text { Cronbach } \\
\text { Alpha }\end{array}$ \\
\hline \multirow[t]{5}{*}{ MOD } & & & & & $\begin{array}{c}332.47 \\
(336.23)\end{array}$ & .857 \\
\hline & Remote entry & .934 & 2.981 & 74.5 & $\begin{array}{c}103.14 \\
(112.36)\end{array}$ & \\
\hline & Shifting resp. & .867 & .642 & 16.0 & $\begin{array}{c}102.46 \\
(109.80)\end{array}$ & \\
\hline & Reorg. & .889 & .209 & 5.2 & $\begin{array}{c}55.97 \\
(79.21)\end{array}$ & \\
\hline & Min. values & .937 & .168 & 4.2 & $\begin{array}{c}70.90 \\
(88.81)\end{array}$ & \\
\hline \multirow[t]{5}{*}{ ENV } & & & & & $\begin{array}{c}525.87 \\
(280.01)\end{array}$ & .757 \\
\hline & Customer & .965 & 2.418 & 60.4 & $\begin{array}{c}192.90 \\
(116.01)\end{array}$ & \\
\hline & New technology & .615 & .657 & 16.4 & $\begin{array}{l}148.50 \\
(97.74)\end{array}$ & \\
\hline & Global trade & .856 & .609 & 15.2 & $\begin{array}{c}98.59 \\
(80.66)\end{array}$ & \\
\hline & Competitor & .638 & .316 & 7.9 & $\begin{array}{c}85.87 \\
(80.66)\end{array}$ & \\
\hline
\end{tabular}

According to Chatterjee and Price (1977), "It is suggested that a VIF (variance inflation factor) in excess of 10 is an indication that multicollinearity may be causing problems in estimation." Chatterjee and Price also state that when performing principal components analysis, one should look for big jumps in the Eigenvalues.

When collinearity statistics were evaluated, the VIF's were between 1.082 and 2.041 for the nine dependent variables. Based on Chaterjee and Price, since no VIF was over 10 , we can assume that multicolinearity is not causing problems in estimation. Furthermore, in examining Eigenvalues in principal components analysis, there were no big jumps in Eigenvalues. All Eigenvalues were under 1 indicating that multicollinearity is not causing problems in estimation.

Finally, the Durbin-Watson statistic $(d)$ is 1.86 at .05 level of significance. In a one-sided test against alternatives $\mathrm{p}>0, \mathrm{~d}=1.86$ is higher than the upper limit of 1.76 for $\mathrm{k}=9$ and $\mathrm{n}=64$. Thus, $d$ is not significant and we conclude that there does not appear to be a problem in serial correlation. This analysis indicates there is no need to revise the proposed model. 
Table 4

Correlation matrix for independent variables

\begin{tabular}{lccccccccc}
\hline & $\mathbf{1}$ & $\mathbf{2}$ & $\mathbf{3}$ & $\mathbf{4}$ & $\mathbf{5}$ & $\mathbf{6}$ & $\mathbf{7}$ & $\mathbf{8}$ & $\mathbf{9}$ \\
\hline 1 & 1.00 & .077 & .173 & .090 & $.287^{\mathrm{a}}$ & $.356^{\mathrm{b}}$ & .080 & .207 & .150 \\
2 & .077 & 1.00 & .170 & .032 & .120 & .100 & -.020 & .005 & -.073 \\
3 & .172 & .170 & 1.00 & $.650^{\mathrm{b}}$ & .083 & .229 & .147 & .062 & .232 \\
4 & .090 & .032 & $.650^{\mathrm{h}}$ & 1.00 & -.034 & .141 & .121 & -.136 & .034 \\
5 & .287 & .120 & .083 & -.039 & 1.00 & $.405^{\mathrm{h}}$ & .188 & $.411^{\mathrm{b}}$ & .197 \\
6 & .356 & .096 & .229 & .141 & $.405^{\mathrm{h}}$ & 1.00 & -.005 & .223 & .116 \\
7 & .080 & -.020 & .147 & .121 & $.188^{\mathrm{b}}$ & -.005 & 1.00 & .163 & $.134^{\prime \prime}$ \\
8 & .207 & .005 & .062 & -.136 & .411 & .223 & .134 & $.317^{\prime \prime}$ & 1.00 \\
\hline
\end{tabular}

"significant at $\mathrm{p} \leq .05$

${ }^{\mathrm{b}}$ significant at $\mathrm{p} \leq .01$

$1=$ Mod Act unccrtainty; $2=$ Other uncertainty; $3=$ Decision-maker experience; $4=$ Decision-maker age; $5=$ Firm size; $6=$ Formal planning; $7=$ Business age; $8=$ Technology expertise; $9=$ Formalization

Table 5

Results of multicollinearity diagnostics

\begin{tabular}{lccc}
\hline Variable & VIF & Eigenvalue & $\begin{array}{c}\text { Durbin-Watson } \\
\text { Statistic }\end{array}$ \\
\hline & & & $\mathrm{d}=1.86$ \\
& & $\mathrm{~d}^{\mathrm{u}}=1.76$ \\
Mod Act uncertainty & 1.205 & .688 & \\
Other uncertainty & 1.082 & .402 & \\
Decision-maker experience & 2.041 & .365 & \\
Decision-maker age & 1.894 & .316 & \\
Firm Size & 1.461 & .210 & \\
Formal Planning & 1.368 & .144 & \\
Business age & 1.097 & .109 & \\
Technological expertise & 1.364 & .002 & \\
Formalization & 1.215 & .016 & \\
\hline
\end{tabular}

\section{Results}

Regression analysis was conducted to test the hypotheses. The results of the regression analysis as shown in Table 6 reveal that the proposed model is fairly 
robust. Its $\mathrm{F}$ value (3.45) is significant at $\mathrm{p}<.10$ and the model explains $26 \%$ of the variability in the dependent variable (i.e., service changes). Additionally, the regression coefficient signs for the statistically significant variables are in the expected direction.

For this study, three of the hypothesized explanatory variables were statistically significant at $\mathrm{p} \leq .10$. The variables include: 1) Mod Act uncertainty, 2) organization size, and 3) decision-maker age. The standardized betas indicate that organization size $(\mathrm{B}=.32)$ has somewhat more predictive strength with respect to NCBFAA customs brokers' momentum to change offerings than does Mod Act uncertainty $(\mathrm{B}=.22)$ and decision-maker age $(\mathrm{B}=-.26)$. However, all three have relatively moderate predictive power. Thus, the regression results support Hypothesis 1a, Hypothesis 2 and Hypothesis 7. That is, as perceived Mod Act uncertainty (remote entry uncertainty) and organization size increase, and decision-maker age decreases, the NCBFAA customs brokers' momentum to change offerings increases.

\section{Table 6}

Results of regression analysis of independent variables effect on service changes

\begin{tabular}{|c|c|c|c|c|c|}
\hline $\begin{array}{l}\text { Independent } \\
\text { Variables } \\
\end{array}$ & F Value & Adj. $\mathbf{R}^{2}$ & Sig F & St. B & Sig T \\
\hline Model & 3.496 & .263 & $.002^{\mathrm{b}}$ & & \\
\hline \multicolumn{4}{|l|}{ Firm size } & $.319^{b}$ & $.018^{a}$ \\
\hline \multicolumn{4}{|c|}{ Other uncertainty: } & .168 & .141 \\
\hline \multicolumn{6}{|l|}{ Customer } \\
\hline \multicolumn{3}{|c|}{ Formal planning } & & .133 & .299 \\
\hline \multicolumn{3}{|c|}{ Mod Act uncertainty: } & & .220 & $.070^{\mathrm{n}}$ \\
\hline \multicolumn{6}{|l|}{ Remote entry } \\
\hline \multicolumn{3}{|l|}{ Business age } & & -.082 & .471 \\
\hline \multicolumn{3}{|c|}{ Decision-maker age } & & -.263 & .083 \\
\hline \multicolumn{3}{|l|}{ Formalization } & & -.170 & .160 \\
\hline \multicolumn{3}{|c|}{ Decision-maker experience } & & -.096 & .538 \\
\hline \multicolumn{3}{|c|}{ Technological expertise } & & -.176 & .168 \\
\hline
\end{tabular}

"T significant at $\mathrm{p}<.10$

${ }^{\mathrm{h}} \mathrm{F}$ significant at $\mathrm{p}<.10$

\section{Discussion and Implications}

This study provides a model that examined NCBFAA decision-makers' perceived external environment uncertainties in light of organization and decision- 
maker characteristics to predict decision-maker momentum to change offerings to better "fit" a dynamic industry environment. The empirical findings include a fairly robust model and findings of significance for three dependent variables with respect to predicting decision-maker momentum to change offerings. These variables are: organization size, decision-maker age and Mod Act uncertainty. These empirical findings provide information to aid in answering the question: Can a scientific process be used to predict decision-maker momentum to change offerings as an antecedent to realigning with a new industry environment?

\section{Decision-maker Momentum to Change Offerings}

Most importantly, the empirical findings in this research provide support for Dutton and Duncan's conceptual theory that the level of decision-maker momentum to change offerings is related to both decision-makers' perceptions of uncertainty significance and response feasibility. In their work, they define response feasibility as, both, resource availability and risk propensity of decision-makers. It is interesting that the three significant dependent variables in this research are: Mod Act uncertainty (regulatory uncertainty creating a dynamic environment for the customs broker industry), decision-maker age (as an indicator of risk propensity) and organization size (with respect to available resources). Furthermore, the findings for these three variables support previous literature mentioned in this article with respect to the direction of these relationships.

Those variables that were not significant predictors of NCBFAA decisionmaker momentum to change offerings are important because the model is designed to help decision-makers focus on: 1 ) the significant uncertainties culled from a list of key uncertainties for the industry at that point in time, 2) significant organizational and decision-maker characteristics, and 3) how the significant and nonsignificant findings may be useful to the decision-makers in the individual firms as they seek to realign to a new industry environment. For example, if organization size is positively related to decision-maker momentum to change offerings, then decision-makers of small organizations can use this information to identify resource alternatives if deemed necessary for the organization's health.

\section{Mod Act uncertainty and decision-maker momentum to change offerings}

The positive relationship between Mod Act uncertainty (i.e., remote entry uncertainty) and decision-maker momentum to change offerings is important for two reasons. First, the use of factor analysis in determining uncertainty significance provides a scientific method for inclusion of significant uncertainties in the regression analysis. To clarify, only perceptions of high uncertainty (Eigenvalue $>1$ ) are included in the regression analysis. Those perceived to be of low uncertainty by the decision-makers are eliminated in factor analysis from inclusion in the model. It is important to note that while customer uncertainty in "other uncertainty" was significant in factor analysis, it was not significant in 
the model. The nonsignificant variables are important because decision-makers can focus on the significant variables as they seek a timely response to uncertainty. This supports Dutton and Duncan's position that decision-makers must first determine a high or low significance for uncertaintics prior to evaluating response feasibility.

Second, these findings support previous research with respect to regulatory and technological uncertainty creating dynamic environments. Birnbaum (1984) states that regulatory and technological uncertainties create more dynamic and turbulent environments. He argues that a timely efficient response is required in order to sustain competitive advantage and avoid organization failure. Because remote entry (increased automation) uncertainty was the one factor in four in the broad Mod Act uncertainty variable that was significant (with an Eigenvalue greater than one), we find support for Birnbaum's contention that regulatory and technological uncertainty do create a more dynamic environment. As a result, these uncertainties require a timely efficient response in order to sustain competitive advantage and/or avoid organization failure.

\section{Organization size and decision-maker momentum to change offerings}

The positive relationship between organization size and decision-maker momentum to change offerings provides support for the body of literature presented with respect to resource availability. Organizations with more available resources will have a higher decision-maker momentum to change offerings in response to a significant uncertainty.

\section{Decision-maker age and decision-maker momentum to change offerings}

Finally, the negative relationship between decision-maker age and decisionmaker momentum to change offerings supports the body of literature presented in this article taking the position that younger decision-makers are likely to have a greater risk propensity than older decision-makers in responding to a significant type of uncertainty. This finding also supports Dutton and Duncan's contention that risk propensity is an important factor when determining response feasibility. It is possible for an organization's decision-makers to perceive an uncertainty as highly significant. Yet, because of either unavailable resources or low risk propensity decision-makers may be unwilling to enact many responses. The result of which may be a low decision-maker momentum to change offerings in response to a significant uncertainty where a response may be required for the organization's health.

\section{Practical Applications for Predicting Decision-maker Momentum to Change Offerings}

The robustness of this model indicates decision-maker momentum to change offerings can be predicted. The F value (3.45) is significant at $\mathrm{p}<.10$, and the model explains $26 \%$ of the variability in the dependent variable (i.e., service changes). We were pleased to find, through rigorous diagnostics for 
multicollinearity, that serial correlation did not appear to be present. These diagnostics included ridge regression analysis, principal components analysis, and a Durbin-Watson test. All three tests provided consistent findings that serial correlation was not present among the nine dependent variables in the proposed model.

In answer to the question, "Can predicting decision-maker momentum to change offerings in response to environmental uncertainty be an important antecedent to organizational change?" We answer "yes" and propose the model has practical implications for decision-makers as a complex strategic integration tool (Burgelman \& Doz, 1997). We believe the model is especially useful for industry associations, where there is variation in decision-maker demographic variables, organization size, and organizational characteristics for regression analysis. Decision-makers can benefit from the additional knowledge of uncertainties gained by surveying many industry members regarding their perceptions of uncertainties. This added information can be useful as decisionmakers aid their organization in realigning to the new environment. Additionally, the flexibility of culling and modifying key uncertainties in the survey for the industry at a given point in time has practical value for decision-makers seeking to realign in a timely manner to specific environmental uncertainties.

For example, if thorough research is done to identify a list of several uncertainties facing an industry at a particular point in time, and the results reveal that for the group of decision-makers surveyed, regulatory uncertainty and customer uncertainty were significant, then decision-makers can focus their organization's attention on these uncertainties. Moreover, important insight can be gained by these organizations with respect to organizational and decision-maker demographics relative to their organization and their decision processes. For example, if technology is determined to be related to decision-maker momentum to change offerings, then small organizations that do not have the necessary technological expertise may explore ways to acquire more technological expertise (e.g., strategic alliances) to maintain or gain competitive advantage. Thus, the proposed model may be seen as a link between complex strategic integration tools and management control systems for alerting decision-makers to perceived changes in the external environment, potential business risks or knowledge gaps in critical areas. Future research may explore this link further.

While this research generated information on perceived intended service changes, the scope of this research was limited to predicting decision-maker momentum to change offerings in response to environmental uncertainty. Future research may wish to focus on how the NCBFAA members moved from strategic intent to strategic response through resource allocation to intended service changes. 


\section{References}

Bamford, C. E., Rogers, P. R., \& Miller, A. (1999). Transformation of strategic types: An examination of the internal antecedents to organizational change. Journal of Business Strategies. 16 (2), 135-149.

Birnbaum, P. H. (1984). The choice of strategic alternatives under increasing regulation in high technology companies. Academy of Management Journal, 27 (3), 489-510.

Boeker, W. (1997). Strategic change: The influence of managerial characteristics and organizational growth. Academy of Management Journal, 40, 162-170.

Boyd, B. K., Dess, G. G., \& Rasheed, A. M. A. (1993). Divergence between archival and perceptual measures of the environment: Causes and consequences. Academy of Management Review, 18 (2), 204-226.

Burgelman, R. A. \& Doz, Y. (1997). Complex strategic integration in the lean multibusiness corporation. Fontainebleau, France. INSEAD Working Paper Series.

Carpenter, M. A. \& Frederickson, J. W. (2001), Top management teams, global strategic posture, and the moderating role of uncertainty. Academy of Management Journal, $44(3), 533-545$.

Chatterjee, S. \& Price, B. (1977). Regression analysis by example. New York: John Wiley \& Sons, Inc.

Child, J. (1972). Organization structure, environment, and performance: The role of strategic choice. Sociology, 6, 1-22.

Duncan, R. B. (1972). Characteristics of organizational environments and perceived environmental uncertainty. Administrative Science Quarterly, 17, 313-327.

Dutton, J. E. \& Duncan, R. B. (1987). The creation of momentum for change through the process of strategic issue diagnosis. Strategic Management Journal, 8, 279-295.

Gersick, C. J. G. (1994). Pacing strategic change: The case of a new venture. Academy of Management Journal, 37 (1), 9-45.

Hambrick, D. C. \& Mason, P. A. (1984). Upper echelons: The organization as a reflection of its top managers. Academy of Management Review. 9 (2) 193-206.

Hambrick, D. \& Finkelstein, S. (1987). Managerial discretion: A bridge between polar views of organizational outcomes. Research in Organizational Behavior. 9 (2), 269 406.

Hamel, G. \& Prahalad, C. K. (1989). Strategic intent. Harvard Business Review, MayJune, 63-76. 
Hart, P. \& Mellons, J. (1970). Management youth and company growth: A correlation? Management Decision, 4, 50-53.

Hitt, M. A. \& Tyler, B. B. (1991). Strategic decision models: Integrating different perspectives. Strategic Management Journal, 12, 327-351.

Hrebiniak, L. G. \& Snow, C. C. (1980). Strategy, distinctive competence, and organizational performance. Administrative Science Quarterly, 25, 317-336.

Hult, G. T., Hurley, R. F., Giunipero, L. C., \& Nichols, E. L. (2000), Organizational learning in global purchasing: A model and text of internal users and corporate buyers. Decision Sciences, 31, 293-325.

Jones Carr, C. M. (1997). Unpublished thesis (copyright TX5-013-120): The customs modernization and informed compliance act: the customs broker industry's perceptions of key changes, uncertainty and implications. Ames: Iowa State University.

Jones Carr, C. M. \& Crum, M. R. (1995). The U.S. customs modernization and informed compliance act: Implications for the logistics pipeline. The International Journal of Logistics Management, 6, 67-81.

Jovanovic, B. (1982). Selection and evolution of industry. Econometrica, May, 649-70.

Kimberly, J. R. \& Evanisko, M. J. (1981). Organizational innovation: The influence of individual, organizational, and contextual factors on hospital adoption of technological and administrative innovations. Academy of Management Journal, 24 (4), 689-713.

Kukalis, S. (1989). The relationship among firm characteristics and design of strategic planning systems in large organizations. Journal of Management, 15 (4), 565-579.

Lawrence, P. R. \& Lorsch, J. W. (1967). Organization and environment: Managing differentiation and integration. Boston: Harvard Business School Press.

Lewis, G. J. \& Harvey, B. (2001). Perceived environmental uncertainty: The extension of Miller's scale to the natural environment. Journal of Management Studies, 38 (2), 201-233.

Lieberson, S. \& O'Connor, J. F. (1972). Leadership and organizational performance: A study of large corporations. American Sociological Review, 37, 117-130.

Link, A. N. \& Bozeman, B. (1991). Innovative behavior in small-sized organizations. Small Business Economics, September, 179-84.

Miles, R. E. \& Snow, C. C. (1978) Organizational strategy, structure, and process. New York: McGraw Hill.

Mintzberg, H. (1979). The structuring of organizations. Englewood Cliffs, N.J.: PrenticeHall. 
Mukherji, A., Desai, A., \& Francis, J. (1999). Reclaiming the environment - organization fit: Matching turnaround strategies to environmental exigencies. Journal of Business Strategies, 16, 27-43.

Miller, K. D. (1993). Industry and country effects on managers' perceptions of environmental uncertainties. Journal of International Business Studies, 24, 693-714.

Mulford, C. L., Shrader, B., \& Hansen, H. B. (1988). Operational and strategic planning in small business. Ames: Iowa State University. North Central Regional Center for Rural Development.

Norburn, D. \& Birley, S. (1988). The top management team and corporate performance. Strategic Management Journal, 9. 225-237.

O'Reilly, C. A. (1982). Variations in decision makers' use of information sources: The impact of quality and accessibility of information. Academy of Management Journal, 25 (4), 756-771.

Papadakis, V. M., Lioukas, S., \& Chambers, D. (1998). Strategic decision-making processes: The role of management and context. Strategic Management Journal, 19, 115-147.

Porter, M. D. (1980). Competitive strategy. New York: Free Press.

Porter, M. E. (1985). Competitive advantage: creating and sustaining superior performance. New York: Free Press.

Quinn, R. E. \& Cameron, K. (1983). Organizational life cycles and shifting criteria of effectiveness: Some preliminary evidences. Management Science, 29, 33-51.

Rajagopalan, N. \& Spreitzer, G. M. (1996). Toward a theory of strategic change: A multilens perspective and integrative framework. Academy of Management Review, 22 (1), 48-79.

Scherer, F. M. (1970). Industrial market structure and economic performance. Chicago. Rand McNally.

Schuman, H. \& Scott, J. (1989). Generations and collective memories. American Sociological Review, 54, 359-381.

Shrader, C. B., Mulford, C. L., \& Blackburn, V. L. (1989). Strategic and operational planning, uncertainty, and performance in small firms. Journal of Small Business Management, 27 (4), 45-60.

Thompson, J. D. (1967) Organizations in action. New York: McGraw-Hill.

Tushman, M. L. \& Romanelli, E. (1985). Organizational Evolution: A metamorphosis model of convergence and reorientation. Research in Organizational Behavior, 7. $171-222$. 
Tushman, M. L., O'Reilly, C., \& Nadler, D. A. (1989). The management of organizations: Strategies, tactics, analyses. New York: Harper \& Row, Publishers.

Variyam, J. \& Kraybill, D. S. (1997). Small organizations' choice of business strategies. Department of Agriculture.

Wiersema, M. F. \& Bantel, K. A. (1992). Top mantgement team demography and corporate strategic change. Academy of Management Journal, 35 (1), 91-121.

Wiersema, M. F. \& Bantel, K. A. (1993). Top management team turnover as an adaptation mechanism: The role of the environment. Strategic Management Journal, 14. 485-504.

Carolyn M. Jones Carr is President of Strategic Response Technologies, Inc. She has an MSBAS from Iowa State University in Business Administrative Sciences with an emphasis in strategic decision processes. Her research and business interests include complex strategic integration models, collaborative learning models, risk management, bootstrap research and critical thinking training. She has industry experience in risk management, logistics and strategy.

Charles B. Shrader, Professor of Management in the College of Business at Iowa State University, received his MBA and Ph.D. degrees from Indiana University. His current research interests include formal strategic planning relationships with organizational performance, corporate social responsibility, social networks and organization structure, boards of directors, and moral reasoning. $\mathrm{He}$ is also interested in collaborative learning in groups, case teaching, and case writing.

Michael R. Crum is a Professor of Transportation and Logistics in the College of Business at Iowa State University. He received his MBA and DBA degrees from Indiana University. His current research interests include employee safety issues and employee satisfaction/retention in the transportation industries, and inter-organizational relationships in the context of integrated supply chain management.

E. James Flynn, Associate Professor of Management in the Babcock Graduate School of Management, Wake Forest University, has BS and PhD degrees from Indiana University, along with an MBA from the University of North Carolina. His research includes the role of innovation in firm performance, building and sustaining multiple competitive advantages, and the management of knowledge workers. His teaching includes strategic management, the role of values in leadership practices and behavior, and social responsibility. 
